\title{
Effect of Medium Chain Fatty Acids and their Derivatives on in vitro Rumen Fermentation
}

\author{
Kazunari Ushida, Yoichi KoJIMA and Ryoji Kawashima* \\ Laboratory of Animal Science, Kyoto Prefectural \\ University, Sakyo-ku, Kyoto-shi 606 \\ * Department of Animal Science, Kyoto University, \\ Sakyo-ku, Kyoto-shi 606
}

(Received March 7, 1991)

Key words : medium chain fatty acid, calcium salts, rumen fermentation

The use of fat for milking cows has been considered a useful supplement to reduce dietary cereal content ${ }^{15)}$. However, excess fat disturb the rumen function ${ }^{14}$. Therefore, the use of so-called rumen-protected "by-pass" fat has been developed in the past two decades, and their effectiveness in high-producing cow has been demonstrated ${ }^{6,11}$. These compounds are made of long chain fatty acids (LCFAs), but medium chain fatty acids (MCFAs; $\mathrm{C}_{6}-\mathrm{C}_{12}$ ) are also available as by-products from the chemical industry and can possibly be used as feed additives for ruminants. However, the use of MCFAs or medium chain triglycerides (MCTs) has been limited to medical uses or infant (preruminant) feeding ${ }^{2-4)}$. Therefore information on their effect, especially of their rumen-protected form on rumen fermentation is still very limited. This experiment was conducted to compare the responses of the in vitro rumen microbial system to MCFAs as free acids, as triglycerides and as calcium salts (rumen-protected form) using a batch fermentation system with four different carbohydrate substrates.

\section{Materials and Methods}

An in vitro batch fermentation system was used to test the effects of MCFAs and their derivatives ${ }^{18)}$. Substrates were reagent grade cellulose powder (Nacalaitesque, Kyoto), maize starch (Nacalaitesque, Kyoto), oat spelt xylan (Aldrich, Milwaukee, USA) and citrus pectin (Wako Pure Chemical, Osaka). Three different forms (free fatty acid (FA), calcium-salt (CA) and triglyceride (TG)) of two MCFAs (ncaprylic $\left(\mathrm{C}_{8}\right)$ and $n$-capric $\left(\mathrm{C}_{10}\right)$ acids) were examined. All forms of MCFAs were obtained from Kao Co. (Tokyo). The in vitro fermentations were conducted with $1 \mathrm{~g}$ substrate, $40 \mathrm{ml}$ of strained rumen fluid, $160 \mathrm{~m} l$ of carbon dioxide-saturated McDougall buffer and $2 \mathrm{ml}$ of ammonium sulfate $(17.6 \%(w / v))$. Each form of the MCFA derivatives was added at $10 \%(\mathrm{w} / \mathrm{w})$ of substrate as FA except for the control flask. MFCA-derivatives are solid at room temperature except for $\mathrm{C}_{8}-\mathrm{FA}$ and -TG. Solid compounds were scraped and added to

中鎖脂肪酸上その誘導体がインビトロルーメン発酵に及ぼす影㗽：牛田一成・小島洋一・川島良治 ${ }^{*}$ (京都府立大

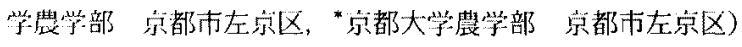


the flasks, liquid compounds were added as droplets. The initial gas phase was $100 \%$ carbon dioxide.

A rumen-cannulated adult wether was used as the rumen fluid donor. This sheep received $400 \mathrm{~g}$ timothy hay and $200 \mathrm{~g}$ of a commercial concentrate mainly containing maize $(17 \%)$, wheat bran $(39 \%)$, soybean cake $(8 \%)$ (Coop dairy-14, Kumiai Shiryo, Kobe) at 09:00 and $18: 00 \mathrm{~h}$. Water and mineral blocks were available to the sheep at all times. The rumen fluid was collected via a cannula just before morning feeding and strained through four layers of surgical gauze. Since the fermentation system was composed of eight units (flasks), four treatments (no-MCFA-Control, FA, CA and TG) of each MCFA $\left(\mathrm{C}_{8}\right.$ or $\left.\mathrm{C}_{10}\right)$ were tested duplicate. In addition to those, another two control flasks were prepared for 0 - $\mathrm{h}$ determinations. MCFAs $\left(\mathrm{C}_{8}\right.$ or $\left.\mathrm{C}_{10}\right)$ were tested on one of four substrates and each batch was tested on two different days. Consequently, 16 batches of incubation (two MCFAs $\times$ four substrates $\times 2$ ) were made. Starch was incubated for $24 \mathrm{~h}$ and the other three substrates were incubated for $48 \mathrm{~h}$ with continual shaking at $39^{\circ} \mathrm{C}$. Fermentation was halted by cooling in a crushed ice bath followed by centrifugation at $1,500 \times \mathrm{g}$ for $30 \mathrm{~min}$. The flasks for 0 - $\mathrm{h}$ determination were treated in the same manner immediately after introduction of the inoculum.

Volatile fatty acids (VFA) in supernatant and the collected gas during incubation were quantitatively analyzed by $\mathrm{GLC}^{16)}$. Production of VFA was calculated as the difference between quantities at $48-\mathrm{h}$ or $24-\mathrm{h}$ vs. $0-\mathrm{h}$. Pellets from cellulose and xylan fermentations were treated by neutral-detergent (ND) to estimate residual substrates (cellulose and NDinsoluble xylan (NDIX)) ${ }^{17)}$. Another series of incubations were carried out in order to determine the effect of MCFAs on starch, pectin and total xylan digestibilities. Each batch was also repeated on two different days.
After fermentation was stopped by cooling in a crushed ice bath, residual xylan, starch and pectin were precipitated by ethanol and centrifuged at $1,500 \times \mathrm{g}$ for $30 \mathrm{~min}$. The initial ethanol concentrations $(\%(\mathrm{v} / \mathrm{v}))$ were 80 for the former two substrates and 88 for pectin. The pellets were washed twice with 80 or $88 \%$ ethanol and successively washed with $90 \%$, $99.5 \%$ and $100 \%$ ethanol and finally with diethylether. Pellets were dried in a desiccator under vacuum. Ethanol-precipitated xylan (EPX) was then determined by the method of KOEHLER ${ }^{13)}$, and starch was extracted by perchloric acid and then measured as free glucose ${ }^{1}$. Pectin was measured as uronic acid after acid hydrolysis ${ }^{14}$. The digestibilities of the substrates were calculated using $0-h$ values as the initial amounts.

The values of digestibilities, gas and VFA within the same MCFA-treatment were analyzed by analysis of variance (Sources of variation were treatment, experimental day and interaction) and, where appropriate, the values were analyzed by Tukey's test to identify treatment difference ${ }^{9}$.

\section{Results and Discussion}

Table 1 shows the effects of MCFAs and their derivatives on carbohydrate digestion in vitro. Cellulose digestion was inhibited by all the MCFA-treatments. Although the effect was statistically significant $(\mathrm{p}<0.05)$, the effect of $\mathrm{C}_{B}$ was relatively small. There was virtually no difference between $\mathrm{C}_{8}$-treatments. While the effects of $\mathrm{C}_{10}$ were more apparent than those of $\mathrm{C}_{8}$. None of $\mathrm{C}_{8}$-treatments significantly affected xylan digestion. While $\mathrm{C}_{10^{-}}$ treatments significantly reduced xylan digestion and the digestion of NDIX was more affected than that of EPX. The subpopulation which was involved in NDIX-digestion was likely to include different organisms from those in EPX-digestion (or more precisely NDsoluble xylan digestion) and the former subpopulation was possibly more affected by $\mathrm{C}_{10^{-}}$ 
USHIDA, KOJIMA and KaWASHIMA

Table 1. Effect of medium chain fatty acids on carbohydrate digestion ( $\not 6$ digested during incubation ${ }^{11}$ ) in vitro ${ }^{21}$

\begin{tabular}{|c|c|c|c|c|c|c|c|c|c|c|}
\hline & \multicolumn{5}{|c|}{ Caprylic acid } & \multicolumn{4}{|c|}{ Capric acid } & \multirow[b]{2}{*}{ SEM } \\
\hline & Control $^{3)}$ & $\mathrm{CA}$ & $\mathrm{TG}$ & FA & SEM & Control & $\mathrm{CA}$ & TG & FA & \\
\hline Cellulose & $92.3^{\mathrm{a}}$ & $86.9^{\circ}$ & $89.2^{\circ}$ & $90.7^{a b}$ & 0.41 & $92.1^{\mathrm{a}}$ & $41.6^{\mathrm{b}}$ & $66.7^{c}$ & $25.9^{d}$ & 2.43 \\
\hline \multicolumn{11}{|l|}{ Xylan } \\
\hline NDIX $^{41}$ & 82.0 & 79.6 & 81.5 & 81.3 & 0.47 & $80.4^{a}$ & $49.6^{b}$ & $56.3^{b}$ & $24.7^{c}$ & 1.34 \\
\hline $\mathrm{EPX}^{5)}$ & 92.1 & 91.0 & 92.8 & 92.3 & 0.33 & $92.0^{\mathrm{a}}$ & $71.6^{\mathrm{b}}$ & $94.0^{\mathrm{a}}$ & $75.0^{\circ}$ & 0.52 \\
\hline Pectin & 72.8 & 68.5 & 73.4 & 70.9 & 1.55 & 71.5 & 70.4 & 75.6 & 70.5 & 1.18 \\
\hline Starch & 98.6 & 98.8 & 98.8 & 99.4 & 0.10 & 98.8 & 98.9 & 98.8 & 98.7 & 0.05 \\
\hline
\end{tabular}

1) Starch was incubated for $24 \mathrm{~h}$, other three substrates were for $48 \mathrm{~h}$.

2) Values within a same row within a same batch of MCFA sharing different superscripts differ significantly $(p<0.05)$.

3) Control, no MCFA; CA, Ca-soap; TG, triglyceride; FA, freo acid.

4) Neutral detergent insoluble xylan.

5) Ethanol-precipitated xylan (=total xylan).

treatments. Partial solubilization of hemicellulose by ND-treatment is well known. Indeed, ND-treatment solubilized a significant part (approximately 40\%) of xylan used in this experiment. This suggests that physico-chemical properties of NDIX may be different from those of ND-soluble xylan and such difference in structure could select a specific population for each xylan fraction. Unlike cellulose and xylan digestion, none of the MCFAs-treatments significantly affected the starch and pectin digestion indicating that amylolytic and pectinolytic subpopulations are less sensitive to MCFAs than cellulolytic and hemicellulolytic subpopulations. The fermentation pattern (Data not shown) was not significantly affected except for a few cases. Carbon dioxide production was affected by $\mathrm{C}_{10}$-treatments, particularly by $\mathrm{FA}$, in cellulose and xylan fermentation (20 to $80 \%$ reduction from control). Methane production from cellulose was significantly depressed by $\mathrm{C}_{10}-\mathrm{FA} \quad(60 \%$ reduction from control), but it was unaffected or slightly increased in other cases. Acetate production was significantly depressed by $\mathrm{C}_{10^{-}}$treatments in cellulose and xylan fermentation (20 to $50 \%$ reduction from control). Propionate production from cellulose was depressed by all the treatments, and the effect of $C_{10}$ was the most apparent. Butyrate production was affected by the treatments in a similar manner to methane production. The published information is very limited on the effect of MCFAs on rumen fermentation; the earlier report of BLAXTER and CzERKAWSKI ${ }^{7)}$ and recent report of Grummer and SoCHA ${ }^{10)}$ are only ones available. The former two authors reported that $\mathrm{C}_{10}-\mathrm{FA}$ is three times more inhibitory than $\mathrm{C}_{8}-\mathrm{FA}$ to ruminal methanogenesis and digestion of dietary non-lipid components. Present results principally agree with their earlier observations ${ }^{7)}$ especially those concerned with fiber digestion, but no inhibitory effect of MCFAs on methanogenesis was detected except for cellulose fermentation in this experiment. This suggests that MCFAs are not necessarily toxic to methanogen and antimethanogenic effect of MCFAs may depend on dietary conditions. Blaxter and Czerkawski have concluded that rumen methanogens are sensitive to FA, but this hypothesis has not been futher confirmed in the methanogenic monoculture system and in in vivo trials under various feeding conditions. GRUMmer and Socha have not observed any change in acetate and propionate concentration in the rumen of cows maintained on a mixed diet supplemented with MCT, but have observed a slight increase in 


\section{Effect of MCFA on Rumen Fermentation}

butyrate concentration in the rumen. However, the response of rumen microorganisms to MCT was not measured and no explanation for the fermentation-shift was given. The reasons for augmentation of butyrate are still unclear. Unlike butyrate and methane, reduction in acetate and propionate production in cellulose and xylan fermentation may well be explained by the reduced substrate utilization.

Fatty acids, MCFAs and unsaturated LCFAs in particular, are known to have antimicrobial activities $^{12)}$, but the mode of action against rumen microorganisms has not been established conclusively ${ }^{8)}$. The adsorption of fatty acid or fat onto feed particles and microorganisms is usually considered as the major cause of inhibition of ruminal fiber digestion. Chalupa et al. ${ }^{8)}$ stressed that the melting point of LCFAs determines its toxicity against the rumen microbial system. They demonstrated that LCFAs of lower melting point are more inhibitory to rumen fermentation. Melting points of the compounds which were tested in this experiment, except for $\mathrm{C}_{8}{ }^{-}$and $\mathrm{C}_{10} \mathrm{CA}$, are lower than the temperature at which incubation was run. Therefore TG and FA of both acids were likely to disperse in the culture medium during incubation, and thus, to adsorb on feed particles and microorganisms. Unlike LCFAs, toxicity of $\mathrm{C}_{10}$ was higher, although its melting point is higher than $\mathrm{C}_{8}$. The reasons for higher toxicity of $10_{10}$ are still unknown, but it is unlikely that the melting point was the first determining factor in the case of MCFAs. The structure of $\mathrm{C}_{10}$ (e.g. the chain length which affects the affinity to the membrane) may cause a higher antimicrobial activity.

The effect of derivatization of LCFAs on rumen fermentation was studied by CHALUPA et al. ${ }^{8)}$ who observed that both $\mathrm{CA}$ and TG are virtually inert to rumen fermentation. Such derivatizations are totally effective in the prevention of toxicity even with unsaturated LCFAs. They suggested that insolubility of
$\mathrm{CA}$ in rumen liquid, a lower binding capacity of $\mathrm{CA}$ and $\mathrm{TG}$ to feed particles and bacteria, and a limited microbial activity which releases little FA from $\mathrm{CA}$ and $\mathrm{TG}$ are the major causes for the inertness. However, both types of derivatization failed to prevent the inhibitory action of $\mathrm{C}_{10}$ to fiber digestion in this experimont. Such incomplete prevention of inhibitory effect might be explained, if binding capacity of $\mathrm{C}_{10}$-TG to feed particles and bacteria was high or if the present microbial system was highly lipolytic (or MCT are more readily hydrolyzed than LCFA). The reasons for incomplete prevention of inhibitory effect by $\mathrm{CA}$ are also complex. $\mathrm{C}_{10}-\mathrm{CA}$ was virtually insoluble to culture fluid ; indeed, a significant amount of $\mathrm{C}_{10}-\mathrm{CA}$ appeared to remain intact after $48 \mathrm{~h}$ incubation. CA, in general, releases $\mathrm{FA}$ at low $\mathrm{pH}$, but the $\mathrm{pH}$ of culture fluid af ter incubation ranged between 5.8 and 6.2. Such $\mathrm{pH}$ is not low enough to produce $\mathrm{FA}$ from $\mathrm{CA}$. There are two possibilities which explain the results; the present microbial system could hydrolyse $\mathrm{C}_{10}-\mathrm{CA}$ to release sufficient amount of $\mathrm{FA}$ or $\mathrm{C}_{10}-\mathrm{CA}$ itself was toxic. Although the causes of toxicity are unclear, the present results suggest that the effect of $\mathrm{C}_{10}-\mathrm{CA}$ on rumen fermentation should carefully be examined before the practical usage of MCFAsderivatives. Indeed, our recent in vivo experiment ${ }^{19)}$ indicated that $\mathrm{CA}$ of mixed MCFA $\left(\mathrm{C}_{8}: \mathrm{C}_{10}=\right.$ ca. $\left.1: 1\right)$ significantly reduced fungal and protozoal population sizes, and consequently fiber digestion in rumen, when the compound was given to sheep at $5 \%$ of daily diet.

The present results suggest that $\mathrm{C}_{B}$ and its derivatives would not cause detrimental effects on rumen fermentation (especially fiber fermentation). While $\mathrm{C}_{10}$ had clear negative effects on fiber digestion even with its rumen protected form. Reduction of $\mathrm{C}_{10}$ content in the MCFA-mixture may be recommended in the practical use of MCFAs, but information is still limited (e.g. an optimum dose, a physical form of products etc.). Further studies are 
required in field experiments in order to examine their effects on rumen microbial population and feed utilization of ruminants under production conditions.

\section{Acknowlegements}

The authors wish to thank Prof. J. Simpson, University of Florida, Gainesville, for his help in preparation of this manuscript. The technical contribution of H. TANAKA is also acknowledged. Kao Corporation (Tokyo, Japan) provided financial assistance.

\section{References}

1) ABE, A., Feed analysis based on the carbohydrates and its application to the nutritive value of feeds. Mem. Natl. Inst. Anim. Ind., 2 : 1-75. 1988.

2) Aurousseau, B., P. Thivend and M. VERMOREL, Influence de remplacement d'une partie du suif d'un aliment d'allaitement par de la tricaproine ou de la tricapryline en association à de l'huile de coprah sur la croissance du jeune veau préruminat. Ann. Zootech., 33:219-234. 1984.

3) Aurousseau, B., M. Vermorel, M. Theriez and A. VezinhET, Effects of substitution of tricaprylin or coconut oil for tallow in milk replacers offered to preruminant lambs. Ann. Zootech., 38 : 49-59. 1989.

4) $\mathrm{BACH}, \mathrm{A}$. and P. Metais, Grasses à chaine courtes et moyennes: Aspects physiologiques, biochimiques, nutritionnels et therapeutiques. Ann. Nutr. Alim., $24: 75-144$. 1970.

5) Bach, A., T. Phan and P. Metais, Octanoate metabolism in the isolated perfused rat liver. Arch. Intl. Physiol. Biochim., 83: 99-109. 1975.

6) Bines, J.A., P.E. BRumby, P.E., J.E. Storry, R.J. Fulford and G.D. BrithWAITE, The effect of protected lipids on nutrient intakes, blood and rumen metabolites and milk secretion in dairy cows during early lactation. J. Agric. Sci. Camb., $91:$ 135-150. 1978.

7) Blaxter, K.L. and J.W. Czerkawski, Modifications of the methane production of the sheep by supplementation of its diet. J. Sci. Food Agric., 17 : 417-421. 1966.
8) Chalupa, W., B. Rickabaugh, D.S. Kronfeld and D. Sklan, Rumen fermentation in vitro as infuenced by long chain fatty acids. J. Dairy Sci., 67:1439-1444. 1984.

9) GrLL, J.H., Design and analysis of experiments in the animal and medical science. Iowa State University Press. Ames, Iowa. 1978.

10) Grummer, R.R. and M.T. Socha, Milk fatty acid composition and plasma energy metabolite concentrations in lactating cows fed medium-chain triglycerides. J. Dairy Sci., 72 : 1996-2001. 1989.

11) Hermansen, J.E., Feed intake, milk yield and milk composition by replacing unprotected fat by Ca-soaps for dairy cows. Anim. Feed Sci. Technol., 22 : 193-202. 1989.

12) Horiguchi, H., Bokin bobai no kagaku. 143-148. Sankyo Shuppan. Tokyo. 1982.

13) Kozhler, L.H., Differentiation of carbohydrate by anthrone. Reaction rate and colour intensity. Analytic. Chem., 24: 1576-1579. 1952

14) Miron, J. and M.T. Yokoyama, Ozonetreated lucerne hay as a model to study lucerne degradation and utilization by rumen bacteria. Anim. Feed Sci. Technol., $27: 269-280.1990$.

15) Palmquist, D.L. and T.G. Jenkins, Fat in lactation rations: review. J. Dairy Sci., 63 : 1-14. 1980.

16) Ushida, K., A. MiYazaki and R. KaWASHIMA, Effect of monensin on ruminal gas and VFA production of wethers fed high roughage ration. Jpn. J. Zootech. Sci., 53: 412-416. 1982.

17) Ushida, K., T. Kaneko and Y. KoJima, Effect of presence of large entodiniomorphid protozoa on the rumen bacterial flora, fauna composition of small entodinia and in vitro cellulolysis and xylanolysis. Jpn. J. Zootech. Sci., 58 : 893902. 1987.

18) Ushida, K., H. TANAKA and Y. KoJima, Effect of phenolic acids on gas and volatile fatty acid production by mixed rumen population with or without protozoa. Jpn. J. Zootech. Sci., 60 : 1135-1142. 1989.

19) Ushida, K., M. Umeda, N. Kishigami and Y. KoJIMa, Unpublished observation. 1991. 